\title{
Archivo y memoria de Negros
}

\author{
Arquivo e Memória de Negros
}

Archive and Memory of the Black People

\section{Maria Leandra BIzelLo (1), Letícia Elaine FERREIRA (2)}

(1) UNESP - Universidade Estadual Paulista "Júlio de Mesquita Filho" - Departamento de Ciência de Informação - Campus Marília - Av. Hygino Muzzi Filho, 737, Campus Universitário, CEP. 17525900 - Marília, SP, Brasil, Caixa-Postal: 181 - mleandra23@gmail.com (2) Programa de Pós-Graduação em Ciência da Informação - Caixa-Postal: 181 - UNESP - Campus Marília le_trabalhos@yahoo.com.br

\begin{abstract}
Resumen
En este trabajo se analiza la documentación producida por el Consejo Municipal del Negro en Brasil en cuanto documentación archivística y de rescate de la memoria de los negros. Para ello, se utilizaron como fundamento interdisciplinar la archivología, la memoria y la historia de los movimientos negros en Brasil. Se analizaron los aspectos legales de creación del Consejo del Negro para comprender las relaciones que establece con el gobierno local y el ayuntamiento. El estudio de los movimientos negros resultó fundamental para comprender la constitución de ese archivo, que garantiza de alguna manera la identidad y la participación social, más allá de rememorar acontecimientos pasados de la experiencia colectiva de los negros. Así se percibe como el movimiento negro se hace oficial y legal a través de la documentación asociada al gobierno local, y se observa como se constituye la memoria oficial del movimiento.
\end{abstract}

Palabras clave: Archivos. Memoria. Movimientos Negros. Custodia. Consejo Municipal del Negro.

\section{Introdução}

O arquivo tem sob a sua custódia fundos de interesse público e social para a preservação da memória consolidando direitos coletivos, que ultrapassam a singularidade do indivíduo, e contribui para tornar público registros de pessoas e instituições cujas trajetórias estão intimamente ligadas à história de uma comunidade (Rodrigues, 2005, p. 19).

Neste sentido, o arquivo deve ser um espaço de garantias de integração do indivíduo e dos grupos sociais com seu passado e seu presente, dimensão em que se pode compreender o princípio democrático do exercício da cidadania. Além disso, os arquivos públicos devem evidenciar os registros da legislação e do funcionamento do governo, dos direitos e deveres do cidadão para com o Estado e do Estado para com o cidadão (Bellotto, 1996, p. 8).

O valor histórico e probatório dos documentos permanentes nos aproxima de uma memória

\begin{abstract}
This work analizes the documentation produced by the Municipal Council of Black people in Brazil, both as archival documents and as a rescue innitiative of blacks' memory. For this purpose, we used the interdisciplinary basis of archival science, the concept of social memory and the history of black movements in Brazil. Legal aspects of Black People Council foundation were raised to provide an understanding of the relations it established with the local government and the municipal city hall. The study of Black movements was fundamental to understand the constitution of this archive, which ensures, in some way, the identity and social participation of black people, beyond the reminiscence of past events from the black people' group experience. Thus we perceive how the black movement becomes official and legal through the documentation associated to local government; and, in the same way, we observe how their official memory is constituted.
\end{abstract}

Keywords: Archives. Memory. Black movements. Custody. Municipal Council of the Black People.

materializada. A preservação destes documentos possue dois aspectos importantes: primeiro para o uso da pesquisa científica e segundo para testemunhar as ações do Estado e a garantia dos cidadãos à informação, sendo que ambas as ações buscam legitimar-se no discurso da preservação do patrimônio histórico e da democratização da memória nacional. (Jardim, 1995, p. 3)

Entretanto podemos perguntar se a memória nacional, sinônimo de história oficial, representa e integra todos os grupos sociais, a diversidade social, em suas datas comemorativas como feriados nacionais. Tal indagação nos levou a refletir sobre a documentação oficial referente a grupos sociais até então considerados excluídos da prática cidadã (1) e que com a abertura política no Brasil tiveram a possibilidade de participar da administração pública através dos conselhos municipais.

Como estudo de caso tomaremos a questão dos conselhos municipais de negros pois tal dis- 
cussão nos faz compreender a produção documental desse grupo étnico. Por outro lado, a memória dos negros no Brasil sempre está ligada ao seu próprio passado desprovido de documentos escritos ou ainda, de documentação que the diz respeito produzida apenas por instituições oficiais.

\section{Conselhos municipais: a busca pela democratização da participação política e informacional}

Após anos de ditadura militar a gestão pública no Brasil apresentou modificações a partir de um movimento democrático-popular amplamente divulgado nos anos de 1980. A pressão popular por maior participação política e intervenção na administração pública foi possível com as discussões para a elaboração da Constituição Federal, a Carta Magna, no período de 19861988. Ainda nessa mesma década e abrangendo a de 1990 estados e municípios constituiram suas legislações maiores, isto é, as constituições estaduais e as leis orgânicas municipais.

Para Calderón e Marim (2002, p. 3) a pressão dos movimentos sociais levou a criação de mecanismos de participação popular na administração pública, como os conselhos, que "[...]foram incorporados nos textos constitucionais ou nas leis complementares, alterando, pelo menos no âmbito legal, a engenharia institucional da administração pública". A participação popular na década de 1970 , sob o regime militar, encontrou na Igreja, e particularmente nas Comunidades Eclesiais de Base o caminho para a influência popular na gestão pública de então.

No entanto, tal participação não era institucionalizada ou ainda, não havia mecanismos legais que a ampliassem como parceira gestora e fiscalizadora do poder público em qualquer que fosse o seu âmbito. Como vimos acima, o processo de abertura política e a pressão de movimentos sociais aprofundaram a discussão na sociedade sobre a participação popular na gestão pública. Por outro lado, houve uma espécie de apropriação pelo Estado dos Conselhos, esse processo se dá justamente a partir da sua institucionalização junto ao poder público.

Esse processo e as propostas da participação da sociedade civil, segundo Calderón e Marim (2002), foram considerados por setores políticos conservadores como uma ingerência na gestão pública municipal. Por outro lado, setores políticos progressistas incentivaram a criação desses mecanismos sem, no entanto, estruturarem propostas mais aprofundadas.
Nesse contexto, entre uma efetiva maneira de participação da sociedade civil e um instrumento institucionalizado e apropriado pela elite política houve a proliferação dos Conselhos Municipais no final do século $X X$ e início do século $X X I$ no Brasil. Em praticamente todos os âmbitos sociais os encontramos: conselhos municipais de mulheres, crianças e adolescentes, dos idosos, dos negros, da saúde, da educação, da assistência social, da cultura.

A multiplicação dos conselhos por outro lado é caracterizada pela diversidade dos municípios brasileiros, com realidades sócio-econômicas, culturais, populacionais muito diferentes entre si. Essa diversidade por sua vez também marca a heterogeneidade com que os conselhos são institucionalizados e compõem seus lugares na hierarquia das gestões municipais.

O local e/ou o regional determina a criação dos conselhos à medida que estão fortemente ligados aos problemas e movimentos sociais locais/regionais. Entretanto ao estudarmos os organogramas de muitas gestões municipais percebemos que os conselhos são invisíveis na estrutura hierárquica e organizacional pública.

É importante aprofundar esse aspecto de invisibilidade dos conselhos pois a sua multiplicação também está ligada ás relações que o Estado Federal estabelece com os municípios no âmbito do repasse de verbas públicas. Nesse caso a ação fiscalizadora dos conselhos é importante principalmente nas áreas da educação, saúde, assistência social e criança e adolescente.

Em outras áreas o conselho atua na relação do estado com grupos sociais historicamente excluídos, como os negros, mulheres e idosos. A abrangência se dá, como destacamos, em função das necesidades locais mas detectamos também o uso político da institucionalização de conselhos relativos a esses grupos sociais como uma maneira superficial de modernização e democratização da gestão pública.

Os conselhos municipais nos chamam a atenção ainda para a problemática da sua produção documental como um fator importante para a memória de segmentos sociais antes marginalizados e da participação popular na administração pública. Tal administração ainda tem práticas autoritárias mesmo que pressionada pelos movimentos sociais.

A falta de transparência do lugar do conselho na hierarquia municipal não nos permite identificar com clareza o exercício de suas funções, atividades e competências. Por sua vez, a recuperação da informação, a partir de sua produção 
documental e das relações hierárquicas, fica comprometida.

Para refletirmos um pouco mais sobre as relações entre conselhos e estado enquanto expressão de movimentos sociais estudaremos os Conselhos Municipais de Negros ou da comunidade negra. Antes porém, é importante um estudo sobre como os negros constituíram seus movimentos de resistência e reivindicações no âmbito público no Brasil.

\section{Aspectos dos movimentos negros no Brasil}

Os movimentos negros no Brasil estão ligados ao conceito de racismo e remontam ao século XIX. Segundo Schwarcz (1996, p. 86) em fins desse século, duas correntes opostas trataram da sua evolução: a primeira, dos evolucionistas sociais, afirmava que havia hierarquias entre os homens, no entanto, acreditavam estes cientistas que haveria uma unidade fundamental entre eles. A segunda, os darwinistas sociais, acreditava que a diferença entre os homens era essencialmente uma questão de diferença entre as raças.

No contexto brasileiro, as teorias raciais são crescentemente utilizadas desde 1870, principalmente nos ambientes acadêmicos, que condenavam a miscigenação e destacavam as modificações ontológicas entre os grupos. $O$ índio foi eleito, durante o período Imperial (1822-1889) no Brasil, em uma visão romântica e nativista, como herói nacional, e representava a identidade nacional (Schwarcz, 1996, p. 86-87).

O negro amplamente utilizado como mão-deobra na agricultura caracterizada pelas grandes extensões de terra e monocultura seja da canade-açúcar ou do café, foi um dos extremos da hierarquia social que constituiu a sociedade brasileira: no topo o branco europeu proprietário e administrador de terras e no outro extremo os negros, nativos e mestiços na condição de escravos e "administrados" (Nogueira, 1985).

A substituição da mão-de-obra escrava negra pela mão-de-obra branca livre e quase sempre assalariada, iniciada em meados do século XIX, gerou um impacto social, sobretudo para os negros, caracterizado pelo desinteresse da transformação dos escravos em trabalhadores livres. A transição não foi favorável aos negros que uma vez libertos da escravidão não foram integrados á sociedade. Os efeitos são originários do progressivo desaparecimento da ordem social escravocrata que colocou os ex - escravos na competição com os imigrantes brancos. As oportunidades criadas beneficiaram muito mais imigrantes europeus do que mulatos e negros libertos. (Fausto, 1996, p. 221)

As teorias raciais no Brasil seguiram juntamente com o contexto do debate da abolição da escravidão. Elas classificavam os indivíduos pelo seu aspecto físico e moral, eram as "teorias da diferença". Tal discussão, segundo Schwarcz (1996, p. 98) foi "[...] expulsa dos espaços oficiais e das instituições científicas, mas ganhou os locais de vivência cotidiana e a esfera das relações pessoais".

$\mathrm{Na}$ década de 1930, sobretudo com a publicação de "Casa Grande \& Senzala" de Gilberto Freyre, a mestiçagem é posta como sinal de identidade nacional, já que o autor ressalta o lado positivo e cordial da miscigenação na história brasileira, sem destacar a violência deste sistema - é Gilberto Freyre o inventor do "mito da democracia racial brasileira" (idem).

Outros autores como Roger Bastides e Arthur Ramos reconheceram, no decorrer do século $\mathrm{XX}$, as desigualdades sociais entre brancos e negros e, no entanto, o Brasil é citado como laboratório de civilização em uma visão estrangeira do país. Em outras palavras, o interesse pelas pesquisas era para justamente demonstrar que no território brasileiro se estabelecia a "harmonia entre as raças".

De qualquer maneira há um reconhecimento do preconceito racial no Brasil, e não podemos perder de vista a questão dos próprios negros, como eles se defenderam - e se defendem - e agiram - e agem - no combate às ações sofridas em uma sociedade que os expurga e os condena pela cor da pele. A constituição de agrupamentos que lutam em diminuir práticas que os subjulguem é uma das razões que embasam a luta dos movimentos negros brasileiros.

Tais movimentos estão intimamente ligados aos diversos aspectos da história do Brasil não se confundindo com as visões meramente econômicas ou políticas, mas entrelaçam-se a esses aspectos. A resistência escrava às formas subhumanas de tratamento e sobrevivência no período colonial manifestava-se na má vontade e sabotagem ao trabalho e a revolta ou fuga para os quilombos (2).

Os quilombos representaram as manifestações das vontades dos negros em constituir um movimento de resistência de configuração política. Podemos compreendê-los como experiências organizadas e coletivas que são consideradas "gênese do movimento negro brasileiro" (França, 2007, p. 18).

A abolição enquanto fato político e social não modificou em nada a situação dos negros na 
sociedade brasileira, agravou-a de tal maneira que a questão da exclusão social tornou-se maior que a questão da cor.

Á partir desse ponto levantado percebemos que os movimentos negros durante o século $X X$ lutaram contra o racismo mas também por melhores condições de trabalho e vida. Surgem várias agremiações, clubes e associações em estados da federação com características assistencialistas, recreativas ou culturais.

Simultaneamente aparece a "imprensa negra": jornais publicados por negros e elaborados para tratar de questões de seus interesses, dentre eles não apenas 0 aspecto anti-racial mas também a saúde, habitação e educação dessa população.

A década de 1930 introduz um salto qualitativo no movimento negro com organizações que reivindicavam políticas mais radicais. A Frente Negra Brasileira foi a mais expressiva nesse aspecto e duramente reprimida no governo de Getúlio Vargas entre 1937-1945.

Destacamos, finalmente, a União dos Homens de Cor e o Teatro Experimental do Negro atuantes nas décadas de 1940 a 1960. A ditadura militar do período de 1964 a 1984 reprimiu brutalmente os movimentos sociais e políticos de esquerda e aqueles que reivindicavam participação maior nas soluções dos problemas agudos da sociedade, o movimento negro foi um deles.

Mesmo assim o Movimento Negro Unificado, de 1978, mostrou a resistência e a organização sob uma perspectiva ideológica. No final do século $X X$ e início do XXI o movimento negro "africanizouse", e a busca por uma identidade étnica específica do negro passa a ser incorporada mediante o resgate de suas raízes ancestrais, norteando o comportamento de militância, como por exemplo o uso da palavra negro expressão de orgulho militante e não em seu sentido pejorativo.

\section{Documentação e memória dos negros: notas finais}

A trajetória do movimento negro no Brasil nos mostra como a preservação da memória desse grupo social e étnico dependeu de sua luta contra o racismo e das tentativas de apagamento de sua participação social efetiva e ativa. $O$ negro enquanto escravo não produzia documentação, nem pessoal, nem coletiva. Ele estava submetido aos registros oficiais; mercadoria que era, aparecia nos recibos de compra e venda, nos processos judiciais, nos inventários dos senhores caracterizado e identificado, quase sempre, por um nome e características físicas.
O negro escravo podia reportar-se ás autoridades jurídicas e executivas em circunstâncias injustas por parte de seus senhores, como é o caso de petições requerendo a intervenção para se obter de fato a liberdade já comprada pelo escravo e negada pelo senhor. Nesse caso, por exemplo, ele deveria ser representado por um advogado ou procurador. $\mathrm{O}$ cenário contemporâneo mudou com a maior inserção social $e$ econômica do negro. Ao mesmo tempo constituiu-se, coletivamente, como um movimento social influente, abrindo lentamente espaço de participação política, social, cultural e econômica.

Como vimos as associações, grupos, clubes multiplicaram-se apesar dos obstáculos representados, acima de tudo, pelo racismo. É nesse contexto que a produção de documentos no âmbito oficial e privado referente ao negro aumenta, entretanto a guarda e preservação dessa mesma documentação sofre com o descaso do Estado. Todavia, há casos de conjuntos documentais preservados e custodiados por instituições públicas, é o que acontece com o acervo pessoal do sociólogo Clóvis Moura. O Centro de Documentação e Memória (CEDEM) da Universidade Estadual Paulista "Júlio de Mesquita Filho" - UNESP em São Paulo é a instituição que custodia esse acervo constituído por documentos das suas atividades de pesquisador e militante do movimento negro. Cientista social negro, a documentação que produziu enquanto intelectual nos mostra também a trajetória do grupo social e étnico a que pertencia.

Os conselhos municipais de negros não são os únicos lugares de organização e representação, há a concorrência saudável de uma série de organizações dedicadas á causa negra com os mais diversos interesses, desde o resgate da cultura africana, da memória de ex escravos passadas a seus descendentes até a religião afro-brasileira. A oficialização desse grupo social e étnico não significou que outras formas de organizações deixassem de existir. O Estado, nesse caso, assumiu a dívida histórica com os negros em sua condição social e econômica.

Considerando o arquivo como um lugar de memória é nele que está depositado toda a incumbência do lembrar, do relembrar e do recordar. A memória inscrita nos documentos de arquivo marca a contemporaneidade e concomitantemente afeta a preservação integral de todo presente e da mesma forma, a preservação do passado (Nora, 1993, p. 14).

Com efeito, a necessidade do lembrar, da busca pelo não esquecimento coloca o arquivo como suporte de memória tendo em vista seu poder de materialização, por meio de sua matéria-prima, 
os documentos, os quais permitem as inscrições desta memória. Memória esta capaz de fazer vir à tona a identidade, a história, a cultura dos cidadãos e grupos sociais contribuindo, assim, para a memória individual e coletiva.

As questões aqui analisadas no âmbito do Conselho Municipal do Negro nos possibilita a comprovação de que o arquivo, ou os diversos arquivos, deste movimento social configura-se como dispositivo de memória coletiva da comunidade negra. Constatamos que a identidade negra, no âmbito dos movimentos negros, é de tal forma espelhada em cada indivíduo que a memória coletiva destes movimentos caracteriza-se pela soma das identidades individuais presentes no grupo. A memória pode ser recuperada se os registros documentais das instituições existirem, ou seja, se os arquivos das instituições estiverem minimamente organizados e preservados.

Dessa forma, a rememoração das atividades e ações registradas consistiram na prova de que o conjunto documental produzido pelo Conselho Municipal do Negro torna-se subsídio, suporte, "lugar" da memória do movimento negro nas comunidades em que foi criado e é ativo. Podemos entendê-lo ainda como um ampliador da memória, em meio a outras possibilidades de memória dessa mesma população e um aspecto institucionalizado da luta anti-racial.

\section{Notas}

(1) Este trabalho foi desenvolvido na linha de Pesquisa Informação e Sociedade e inserido nas discussões do Grupo de Estudos Memória do Departamento de Ciência de Informação - UNESP - Campus Marília - SP.

(2) Quilombos eram comunidades constituídas por escravos fugidos durante o período em que vigorou a escravidão no Brasil. Essas comunidades eram independentes, com organização política, social, econômica e cultural próprias.Tais comunidades existiram em todo o continente americano mas recebiam nomes diferentes: palenques (América Espanhola), maroons (América Inglesa), grand marronage (América Francesa) (Reis, João José; Gomes, Flávio dos Santos, 1996.09-25).

\section{Referências}

Bellotto, Heloísa Liberalli (1996). A imagem do arquivista na sociedade e o ensino da Arquivologia. // Arquivo \& História: Revista do Arquivo Público do Estado do Rio de Janeiro. Rio de Janeiro: Arquivo Público do Estado de Rio de Janeiro. 2 (1996).

Calderón, Adolfo Ignácio; Marim, Vlademir (2002). Educação e políticas públicas: os conselhos municipais em questão. // Revista Teias. ISSN 1518-5370. 3:6 (2002) 1-11. http://www.periodicos.proped.pro.br/index.php?journal=r evistateias\&page=issue\&op=view\&path[]=11 . (2010-0708)

Duchein, M. O respeito aos fundos em arquivística: princípios teóricos e problemas práticos. Trad. Maria Amélia
Gomes Leite. // Arquivo \& Administração. 10-14:1 (abr.1982/ago.1986) 14-33.

Fausto, Boris. (1996). História do Brasil. $4^{\text {a}} e d$., São Paulo:Editora da Universidade de São Paulo; Fundação para o Desenvolvimento da Educação, 1996.

França, E. (2007). Olhar panorâmico sobre o movimento negro brasileiro // França, E.; Ruy, J. C; Viera, M. J. Um olhar negro sobre o Brasil: dezoito anos de UNEGRO. São Paulo: Anita Garibaldi, 2007. 15-41. http://www.cedem.unesp.br/ (2010-07-02)

Jardim, José Maria (1995). A invenção da memória nos arquivos públicos// Ciência da Informação. 25:2 (1995) http://revista.ibict.br/index.php/ciinf/article/view/439/397 (2007-09-28)

Nogueira, O. (1985). Preconceito racial de marca e preconceito racial de origem. // Tanto preto quanto branco: estudos de relações raciais no Brasil. São Paulo: T. A. Queiroz, 1985.

Nora, Pierre (1993). Entre memória e história: a problemática dos lugares. // Projeto História: Revista do Programa de Pós - graduação em História e do Departamento de História da Pontifícia Universidade Católica de São Paulo. 10 (dez. 1993) 07-28.

Reis, João José; Gomes, Flávio dos Santos (org.) (1996). Liberdade por um fio: história dos quilombos no Brasil. São Paulo: Companhia das Letras, 1996.

Rodrigues, Ana Célia. (2005) Tipologia documental como parâmetro de classificação e avaliação em arquivos municipais // Cadernos de Estudos Municipais. Universidade do Minho (Portugal). 17/18 (jun a dez 2005) 11-46.

Schwarcz, L. K.M. (1996) Usos e abusos na mestiçagem e da raça no Brasil: uma história das teorías raciais no século XIX. // Revista Afro-Ásia. 18 (1996) 77-101. http://www.afroasia.ufba.br/pdf/afroasia_n18_p77.pdf (2009-11-03)

Recibido: 16-05-2010. Revisado: 10-07-2010

Aceptado: $20-07-2010$ 
